\title{
How 3D printing technologies can contribute into an iterative design process? Case study to hit a drum for Disabled Children
}

\author{
Guillaume Thomann ${ }^{\mathrm{a} *}$, Justine Coton ${ }^{\mathrm{a}}$, Marcel de Gois Pinto ${ }^{\mathrm{a}, \mathrm{b}}$, Julien Veytizou ${ }^{\mathrm{a}}$, François Villeneuve \\ aniversity Grenoble Alpes, Grenoble, France

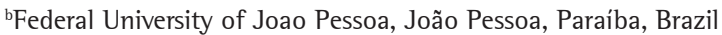 \\ *guillaume.thomann@grenoble-inp.fr
}

\begin{abstract}
In the Assistive Technology area and design for disability, users must be taken into account during the design process. Multidisciplinary design team is constituted and an adapted design methodology used. In this design case study, this team has to develop an electromechanical drumstick dedicated to percussion instruments. Objective is to allow Disabled Children to hit a drum using an automated drumstick. Authors proposed to used of available Rapid Prototyping (RP) Technologies all along the design process. Different RP technologies were manipulated by engineerins and engineering students to be able to validate progressively product functions and news ideas and designs. The results indicates that one RP technology can be chosen in correlation with a new iteration of the design methodology. The availability of RP technologies helps the multidisciplinary team to validate progressively the product according to requirements. This experiment contributes to the development of different prototypes over the years.
\end{abstract}

Keywords

Design for disability. Rapid prototyping. Design product development. Human factor in design. Iteration process.

How to cite this article: Thomann, G., Coton, J., Pinto, M., Veytizou, J., \& Villeneuve, F. (2017). How 3D printing technologies can contribute into an iterative design process? Case study to hit a drum for Disabled Children. Production, v27, e20170047. D01 10.1590/0103-6513.004717

Received: June 19, 2017; Accepted: Sep. 04, 2017.

\section{Introduction}

People with physical disability generally have difficulty to manipulate objects in their environment. This is because their upper limbs may be impaired or the mobility device used may generate discomfort (Pruski, 2010). In many cases, proposing a new human interface to perform a task represents a challenge: the users and their personal capabilities must be taken into account in the design process together with environmental factors. In specialised educational schools, children with cerebral palsy or myopathy not only involved in educational activities but in cultural and social activities too. The AE2M non-profit association ("Adaptation Ergonomique du Matériel Musical" in French ou Ergonomic Adaptation of Musical Devices in english) manages activities to allow physically Disabled Children (DC) to play the music. The musical practice capability highly depends on the type of disability of the person in relation to the instrument and the skills required for this specific instrument. In the case study to hit a drum for DC, it is often impossible for them to hold the drumstick. This context was an opportunity to organise a design project based on:

- The constitution of a multidisciplinary team with the DC to be able to answer correctly possible to the issue; 
- The use of a User Centred Design (UCD) approach which allows the user to be involved all along the design process;

- The use of Rapid Prototyping (RP) technologies that are available in the university and can be used by the member of the multidisciplinary team.

According to Boer et al. (2015), the current contribution to theory to this paper is based on discovery and observations of the case study. In the current case study, not only knowledge of the user's capabilities but also the musical expertise are required. Engineers work with researchers to develop personalized products for playing percussion instruments. The experiment highlights the necessity to work in a multidisciplinary team (musical specialists, physiotherapists, engineers, DC, etc.), and to use adapted design methodology for Assistive Technology (AT).

The research question is about the contribution of the RP technologies in the design process of such a product. That is why the use of additive manufacturing technologies for rapid prototyping will be tested. The AE2M association works in collaboration with Grenoble University to respond to this kind of design projects. In the university, engineers, researchers and students participate, using RP technologies that are available to personalized easily products and interfaces. Generally, various 3D printing machines are used to be able to choose the right final technology link with the current issue. In this paper, authors observed how 3D printing technologies contribute to the design process. Some rapid prototyping technologies will be described in relation to the product features evolution.

This specific case study requires literature reviews about the necessity to evolve in a multidisciplinary team with specialists (technology, healthcare and music in the current case). Then, because of the importance rate of Assistive Product abandonment, the chosen design methodology will be user-centred approach oriented.

\section{State of the art}

\subsection{A multidisciplinary team in the design process}

System designers for disabled people can be divided into two main groups (Sperandio, 2007). The first group of designers works with a set of well-defined user requirements; while seeking a technological solution, they primarily target something practical, which often leads them to discard more advanced technologies. The risk for this group might be to opt for obsolete, unusable or overly expensive technology. The second group of designers focuses on innovative technology and research applications in the disability field. The risk for this group might be to propose solutions for imaginary or non-priority needs. One solution to circumvent these problems is to create a link between these teams of designers and encourage them to work as part of a multidisciplinary team.

Developing assistive technology in multidisciplinary teams constitutes a challenge. Elprama et al. (2013) propose a procedure to bring all actors in the project together using a user centred approach. Authors insist in the writing of a scenario that fix the idea of the future envisioned assistive technology. It continues using questionnaires with all partners. Multidisciplinary meetings are in the centre of the procedure in which the survey and the use case together serve as a basis to come to a hypothetical scenario describing current and future practices. Finally, experiments are required to validate the assumptions in the hypothetical scenario hold. The important phases pointed out are the interviews of the relevant users: the hypothetical scenario will then iteratively evolve to a current practice scenario.

Magnier et al. (2012) have already explored the product development process with DC. In their study, they analyse seventeen design projects involving DC, engineering students and special schools. Three important aspects emerge from the content analysis. (1) Difficulties identified in existing literature arise in the context of their study. (2) Among the difficulties related to the practical barriers of involving DC, one new difficulty in particular is identified, i.e. that of partnering with special schools. (3) While existing literature focuses on the practical barriers, the results of this study show that not all difficulties are related to these barriers. In fact, understanding a user's needs proves to be especially difficult when the product to be designed targets different types of disabled users. This research demonstrates the importance to maintain the motivation of the users (especially children), the family, and the medical staff during the design process. A manner to do this is to show them regularly the evolution of the work, like doing tests and experimentation with new physical prototypes. This study showed the necessity of working not only with engineers and medical professionals, but with as many people as possible who play a role in the context of use: staff at the educational institute, family members, educators, and other DC who interact with the user (Magnier et al., 2012).

In their experiment, Chavarriaga et al. (2014) describe a multidisciplinary research line on technology-based assistive solutions for motor disabilities involving institutions in Colombia and Switzerland. The team was 
constituted from engineers, therapists, designers and end-users from early stages of the design process. As an observation, providing experts from different domains with a common knowledge facilitates the multidisciplinary work, enabling us to initiate experiments on clinical research.

\subsection{From AT product abandonment ...}

The development of AT has produced several benefits for people in difficult situations. However, some studies report on problems with AT, which can lead to product abandonment. Cruz et al. (2016) have performed detailed bibliographic research in this field. Even if the requirements list for the AT product has already been defined, the design process can integrate product abandonment criteria at a later point. In fact, it is possible to link the patient's changing needs with the design process, which should aim to be dynamic rather than static. Traditionally, the most evident reasons are non-acceptance of their handicap and depression, low quality products, social support weaknesses in the individual's environment, architectural barriers, and factors related to rehabilitation (intervention), such as inappropriate instruction and training for product acquisition. The current study shows that products were not being used by the participants for several additional reasons: not believing in their benefits, aesthetic issues, needing a more secure device, and other issues peculiar to each case. The lack of resource monitoring by a specialized professional in assistive technology can be one factor that causes patients to abandon technologies.

\subsection{To the necessity a user-centred design approach}

As Pullin (2011) explains, disabled people as expert co-designers have to be involved in the design approach used in this case. When design meets disability, the diversity of complementary, even contradictory, approaches can enrich each field.

In the case study described in this paper, a user-centred approach is applied to design for disabled users. The aim of the approach is to improve product usability (ease of use and learnability of a human-made object such as a tool or device). The methodology is based on five technical points that the project design must take into account: (1) knowledge of end users, (2) active user participation, (3) appropriate sharing of functions between users and technologies, (4) an iterative approach to design and, finally, (5) the intervention of a multidisciplinary team (ISO 9241-210, International Organization for Standardization, 2010). The iterative process ends when the design solution meets the requirements of the end user.

Coupled with this methodology, different design concepts positioned as user-centred approaches have been reported on (Brangier \& Barcenilla, 2003). The first group of concepts concerns the design of products for a maximum number of users: universal concepts. Story (1998) defines Universal Design as the concept of designing all products and the built environment to be aesthetic and usable to the greatest extent possible by everyone, regardless of age, ability, or status in life. The universal concept group aims to design products that are accessible to and usable by the largest number of users. In contrast to the universal concept, there are specialized concepts. Its aim is to design custom-built or unique products based on the requirements of the user or a specific medical situation.

Universal and specialized concepts thus call on a range of different strategies. The question is "can the notions pertaining to both concepts be used to propose an innovative product design process?" A first step in this direction was taken by the AE2M association and a group of researchers (Veytizou et al., 2013). The design team developed a universal product capable to transform any user environment objects into a personalized interface. The product designed was a piezoelectric chip allowing any user to play percussion instruments. In the context of DC with special needs, the clip allows the musical instrument to be controlled even if the player's ability is specific or limited. This example proves that it is possible to mix both approaches to allow a maximum number of disabled people to play percussion instruments. The study proposed by (Lancioni et al., 2007) evaluates micro switch technology recently introduced for chin and eyelid responses, with two new participants with profound multiple disabilities. It was conducted according to an $A B A B$ design with a 3-week post intervention check. An experimental design, often involving a single subject, wherein a baseline period $(A)$ is followed by a treatment (B). To confirm that the treatment resulted in a change in behaviour, the treatment is then withdrawn (A) and reinstated (B). The results showed that both participants increased their level of responding during the intervention phases and post intervention check compared to the baseline phases. 


\section{Methodology and objectives}

Based on a concrete and real situation in which DC are unable to access a musical instrument, the case study allows to propose design approach based on RP. In accordance with the UCD principles (five technical points), engineers and engineering students develop a product ("control" and "operational" parts) that allows many DC to play percussion instruments in different manners. In this study, the users are not only the DC but anybody likely to interact with the product during the activity: the music teacher, the family, physiotherapists, some friends, etc. The concurrent engineering team and the importance of individual expertise and competencies within the team is essential in this kind of "human" project. The experience of working together over a period of years has enabled the researchers, medical staff and music teachers to develop specific competencies. The A2EM association represents the idea of working together for and with the DC through a simple diagram (Thomann et al., 2008): the AE2M competency triangle (Figure 1). AE2M uses this illustration to promote the importance of all collaborators working together and using their different competencies to develop the product.

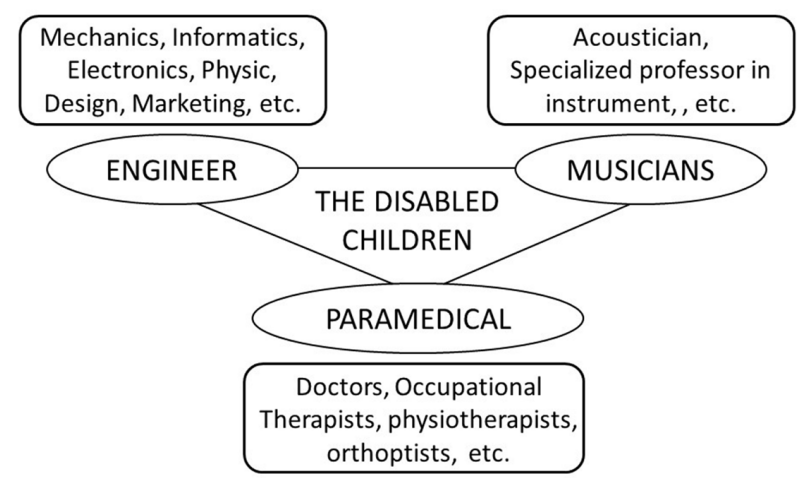

Figure 1. The AE2M competency triangle.

The first version of the product was designed and manufactured by a group of engineering students in 2006 . Other prototypes have been developed to increase functionality and usability up to 2015. Throughout the product development process, the designers refer to the UCD methodology (ISO 9241-210, International Organization for Standardization, 2010). The following list provides some concrete examples of the activities carried out.

- Knowledge of end users: the engineering students, designers and researchers spend much time observing the users (DC and music teacher) and defining their situational context with the medical staff before the start of the design process;

- Active participation of users: all the meetings take place with at least one person from each specialized area (an engineer, a musician and a healthcare professional) and the DC. Photos and videos are recorded for later analysis, especially during the experimental phase with prototypes;

- Appropriate distribution of functions between users and technology: all the users take part in the definition of the product. For example (1) it has to be easy for the family to install the technology, (2) the technology has to meet the requirements of the music teacher and (3) the technology or design chosed has to allow many DC to play the instruments. The ultimate goal of the technology is not to replace the users but to allow them to exploit their capabilities;

- Iterative approach to design: between 2006 and the creation of the first prototype, experiments are performed in real situations allowing the team to test different product functions and experimental setups. The designers implement the iterative process cycle proposed by the researchers: observation and analysis, design, prototype manufacturing, experimentation - observation and analysis, design modification, etc.;

- Participation of a multidisciplinary team: as previously stated, all the meetings involve at least one person from each profession (an engineer a musician and a healthcare professional) and the DC. Competencies are additional between the actors: for example (1) engineers cannot propose any development without the validation of the medical staff (mainly the human capabilities validation) and the family (cost, interaction, etc.). (2) Engineer cannot program any new rhythmic cell in the microcontroller without knowing the music type proposed by the musical teacher. 
It should be noted that the product, an electromechanical drumstick system has to be developed for many DC. Each child has his or her own healthcare specialist working with them on a daily basis. The music teacher is the same for all the DC. Ultimately, he will use the final product to allow the children to play music in the specialized school and during concerts.

During this case study, engineers and engineering students used some RP technologies according to process validation phases and user requirements' evolution. Thus, thanks to the users' active interaction, engineers and researchers had the opportunity to select the most adapted RP technology in function of the design process phase objectives.

\section{Product development}

\subsection{Technological principle of the Electro Mechanical Drumstick System (MEM)}

To be able to understand the necessity to use RP technologies, product concepts have to be described more precisely. The MEM must allow DC to hit a drum with a drumstick. The movement of the DrumStick (DS in Figure 2) is generated with a force produced by a rising ElectroMagnet (EM in Figure 2) and a spin joint.

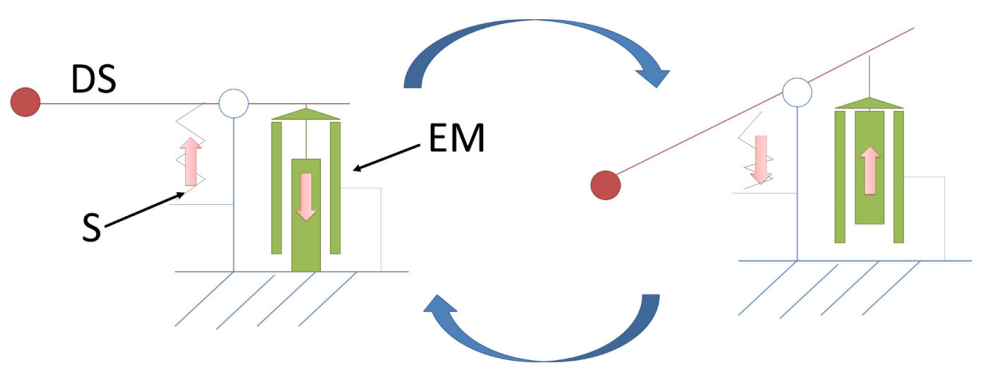

Figure 2. Illustration of the lever (EM: electromagnet; S: spring; DS: drumstick).

A Spring (S in Figure 2) returns the device to its initial position (see Figure 2). The push type EM is made up of a coil and an axle. When activated, the axle is raised causing the drumstick to rotate around its pin. A little spring is located between the end of the coil and the axle to keep them from "sticking" together. When not activated, the electromagnet axle is stopped by the housing and thus keeps a constant course.

The rotating part is made up of a "drum stick holder", and a screw with a smooth body inserted inside the system housing (Figure 3). The screw is fastened to the housing leaving the "drum stick holder" free to rotate around the smooth part of the screw. The drumstick is held on this "drum stick holder" and is located a little higher than the centre of the pin. The drumstick is maintained in position in this "drum stick holder" with the help of another screw.



Figure 3. Drum stick holder assembly CAO model. 
To ensure the drumstick stays in contact with the axle of the electromagnet when it is in its lower position, a spring is placed just after the pin on an extrusion visible in Figure 3.

The electromagnet is positioned in relation to the centre of pin. This precise position for example can constitute one criteria to orient the right choice of the RP technology. The electromagnet is fastened to this housing.

\subsection{RP technologies available in the Grenoble University}

A limited edition of this housing and "drum stick holder" can be easily created using 3D-Printing technologies. There are several processes for making these parts. The availability of multiple RP technologies is an enormous advantage in this of project. It is possible to use the most effective one depending on the situation. All of them can be used to manufacture a customized component, thus meeting the need for this particular product development project. The following section outlines the advantages and drawbacks of each technology used.

- Classical CNC machining (Figure 4): a long and expensive process.

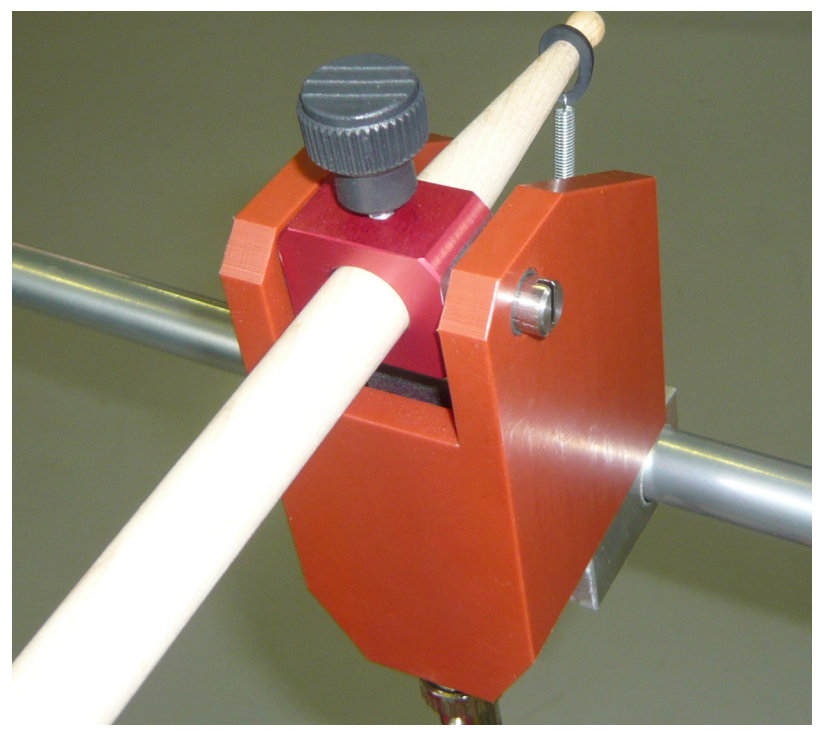

Figure 4. Machined housing and "drum stick holder".

- Zprinter ${ }^{\circledR}$ (Figure 5): this manufacturing process consists in solidifying plaster powder, layer by layer, using a binder.

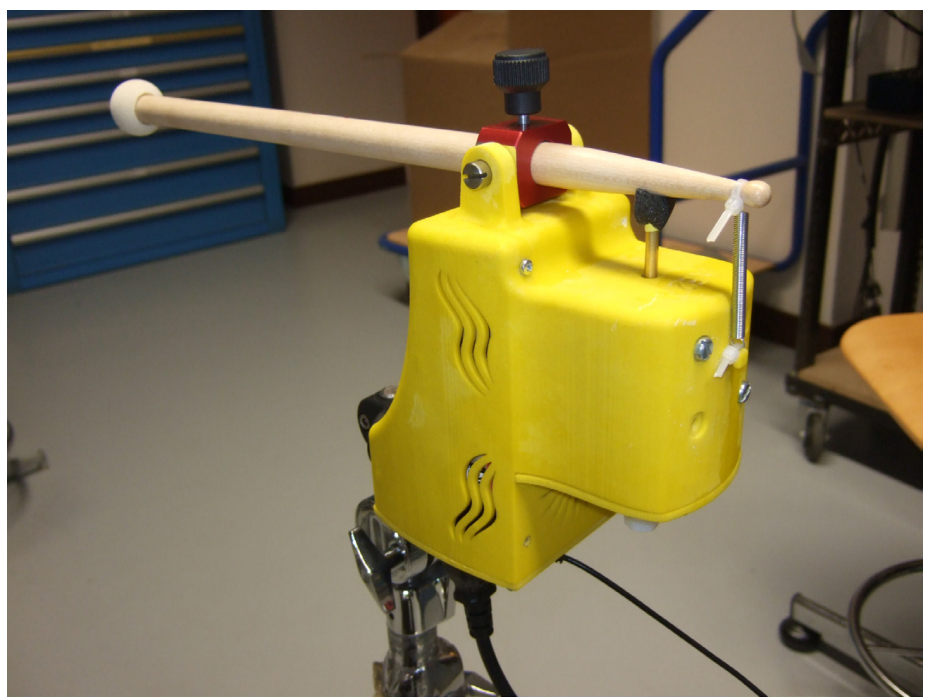

Figure 5. Yellow Zprinter ${ }^{\circledR}$ housing in plaster. 
A lot of shapes are possible but the final product has a low level of rigidness, which is not acceptable for the MEM. Although the part produced is generally not functional, this manufacturing process is ideal for discussing a new solution which is often non-functional;

- Z-builder: this manufacturing process consists in solidifying, layer by layer, a liquid photopolymer using a digital light processor projector. A lot of shapes are possible but supports are necessary. An object produced with this technology is expensive, very brittle and offers little resilience and is hence once more unusable for the MEM;

- Stratoconception: the concept is to machine slide material and, with the help of a positioning insert, to stick the slides together to recreate the final product. This process is not suitable for the housing with thick walls;

- Fused Deposition Modelling (FDM): a plastic string (made of PLA, ABS, etc.) is heated and deposited layer by layer according to the desired shape in order to construct the final object;

- Low-cost type FDM or Rep/Rap (Figure 6): very cheap, but slow to manufacture. Many shapes are possible according to the support structures. These are made of the same material as the part and are therefore likely to leave marks;

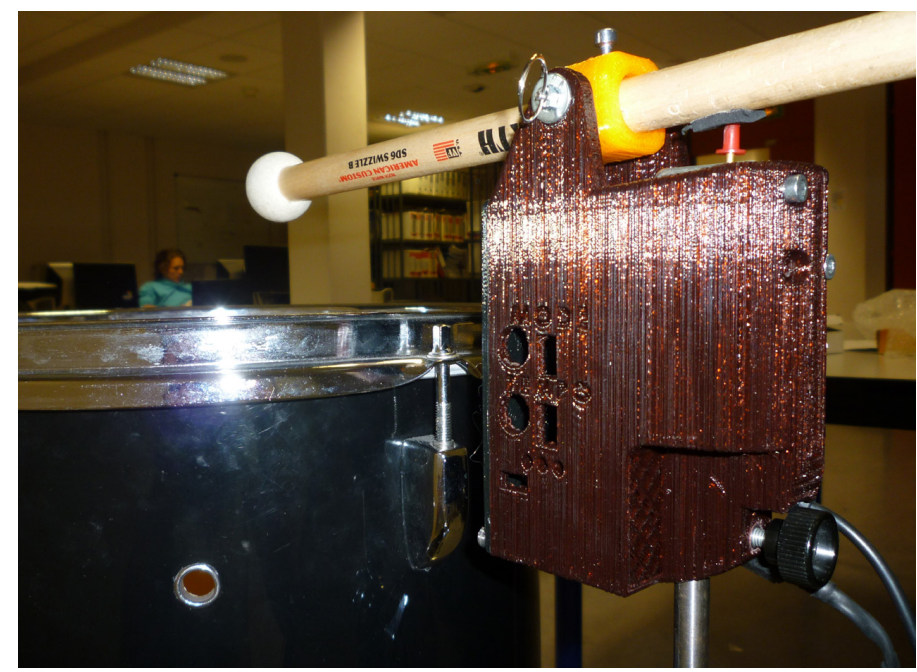

Figure 6. Final version of the MEM using the Rep/Rap manufacturing process.

- Professional FDM: more expensive but more precise and more reliable. Supports are soluble in sodium. This was considered the best technology for the last version of the MEM.

Thanks to the concurrent engineering project context with end-user involvement into the collaborative team, an adequate RP technology is chosen at each iteration to evaluate functionality or modification geometry.

\subsection{Design changes influenced by the users}

As already stated, the ultimate purpose of the product was to allow the users to play a drum. The first prototype was developed and manufactured without the involvement of the DC. The main participant involved in the design of the first version of the product, modelled in Figure 7, was the music teacher.

All the components ensuring the main functions of the device were present. The first idea provided by the music teacher was to link the main rod of the product directly to the drum (Figure 8). Unfortunately, the consequence of this proposal was that the vibrations from the drumstick were transmitted to the entire mechanical system causing instability and damage.

This prototype used a battery connected directly to the MEM. The user interface (button) was connected to the battery. Moreover, the first version of the button interface was too hard to push and could not be used by any of the DC. For this first prototype, the engineers used a standard CNC machine that proved to be too expensive and time-consuming. 


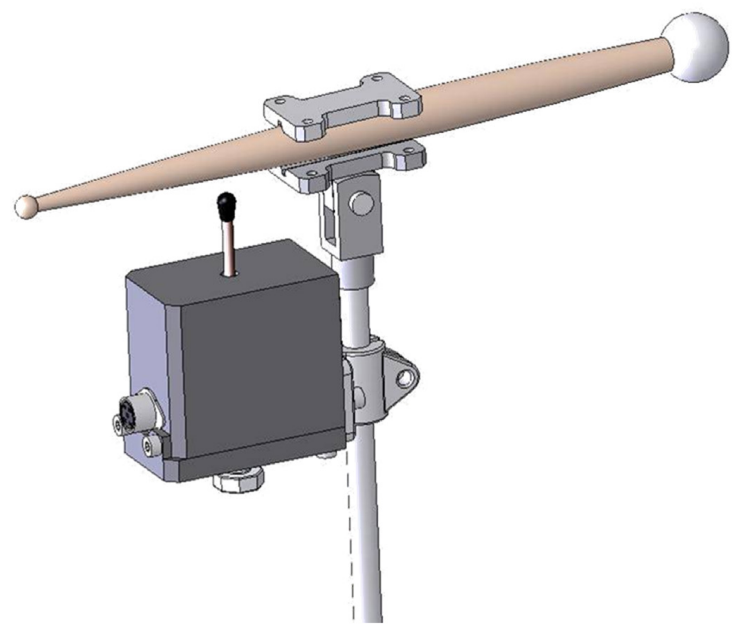

Figure 7. CAO model of the first MEM version.



Figure 8. The first MEM version directly linked to the drum (year 2007).

This prototype convinced the entire design team of the necessity to involve more user knowledge in the design process of the product. Figure 9 shows one of the first experimentations with the physiotherapists and the engineering students together with the DC.

Following a number of technical modifications, many musical experimentations were performed with different DC in the specialized school (Figure 10).

The first two years of user experiences (involving family members, healthcare professionals, the music teacher and the DC) revealed the need to modify the overall product architecture. All the wires and connections of the final prototype were found to be fragile. Moreover, to simplify the assembly of the product for customers, the team decided to put all the electrical parts inside a housing. Only the power supply and user interface were connected to the housing. Figures 11 and 12 show the next version design of the prototype structure. It was manufactured using the plaster Zprinter ${ }^{\circledR}$ (fragile material when thick walls or vibrations) with the aim of checking how easy the components were to assemble by some users and customers.

Finally, thanks to the users' participation and thanks to all the experiments performed with different manufacturing technologies over the course of the design process, the penultimate prototype was produced using the Rep/Rap machine (Figure 6).

Unfortunately, the poor quality of the result and the necessary manual finishing operation forced the designers to select the professional FDM technology for the used final version. Nevertheless, the use of this technology 


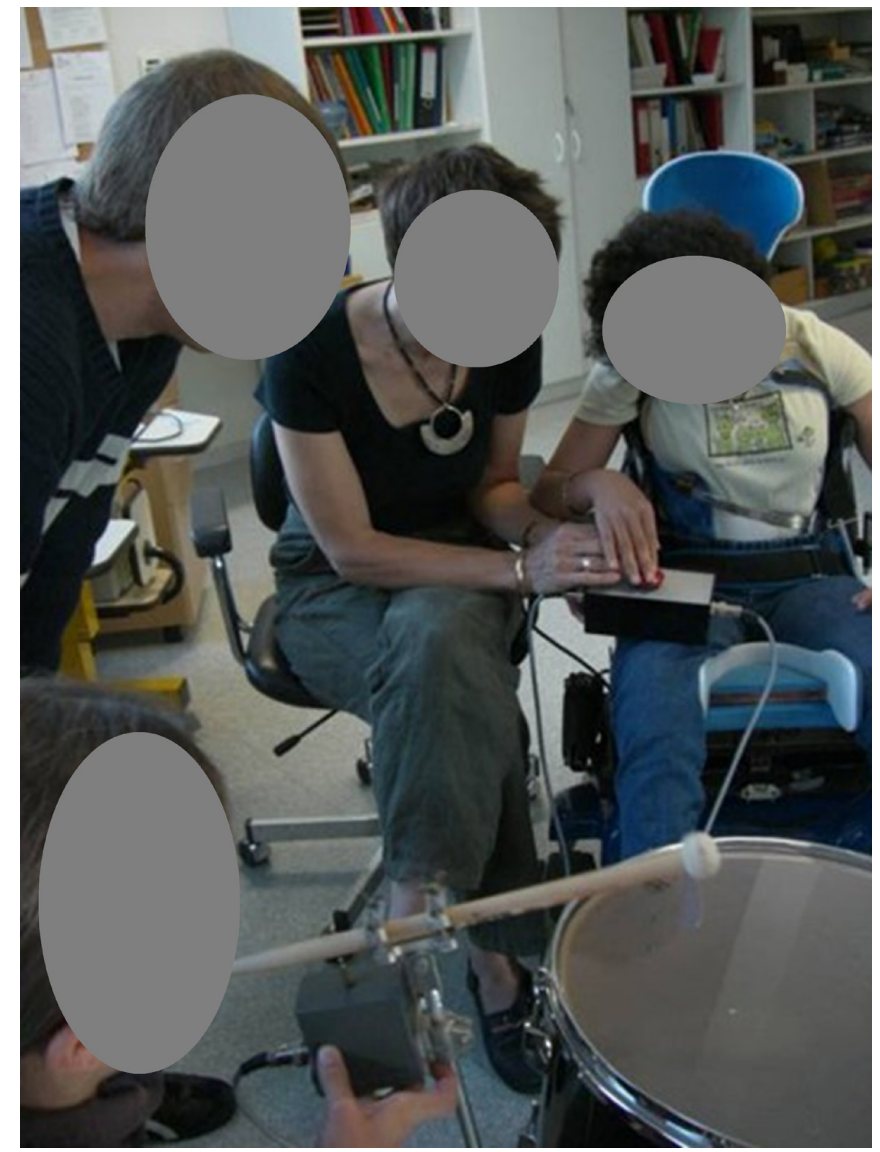

Figure 9. DC using the first prototype with the help of the physiotherapist and in the presence of the engineering students (year 2008).

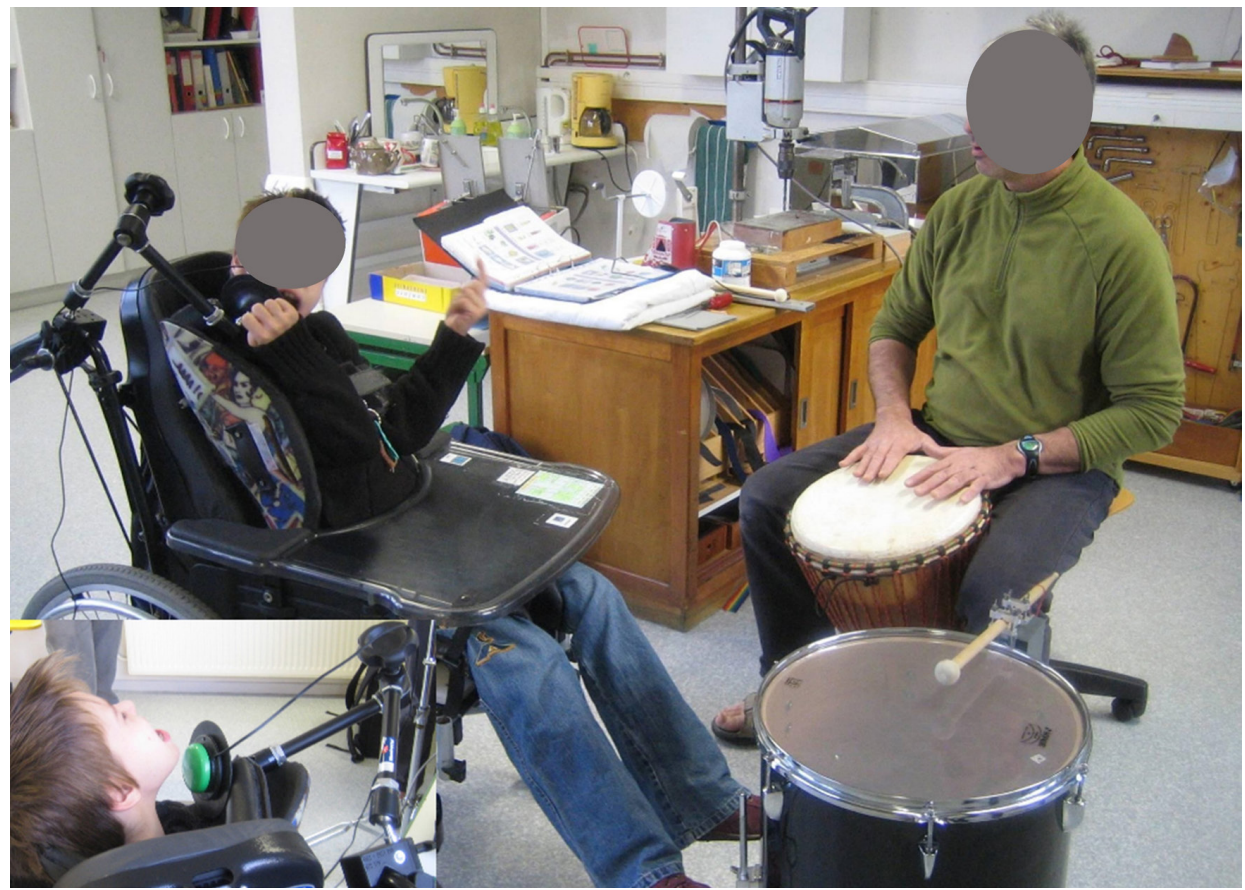

Figure 10. DC using the prototype with the music teacher. 


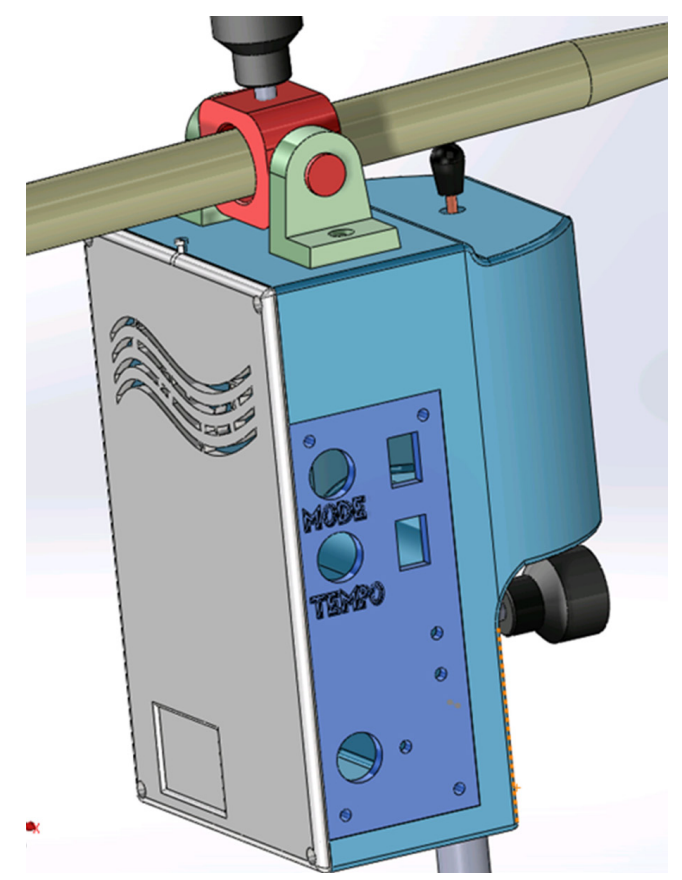

Figure 11. Model of the final version of the MEM (year 2011).

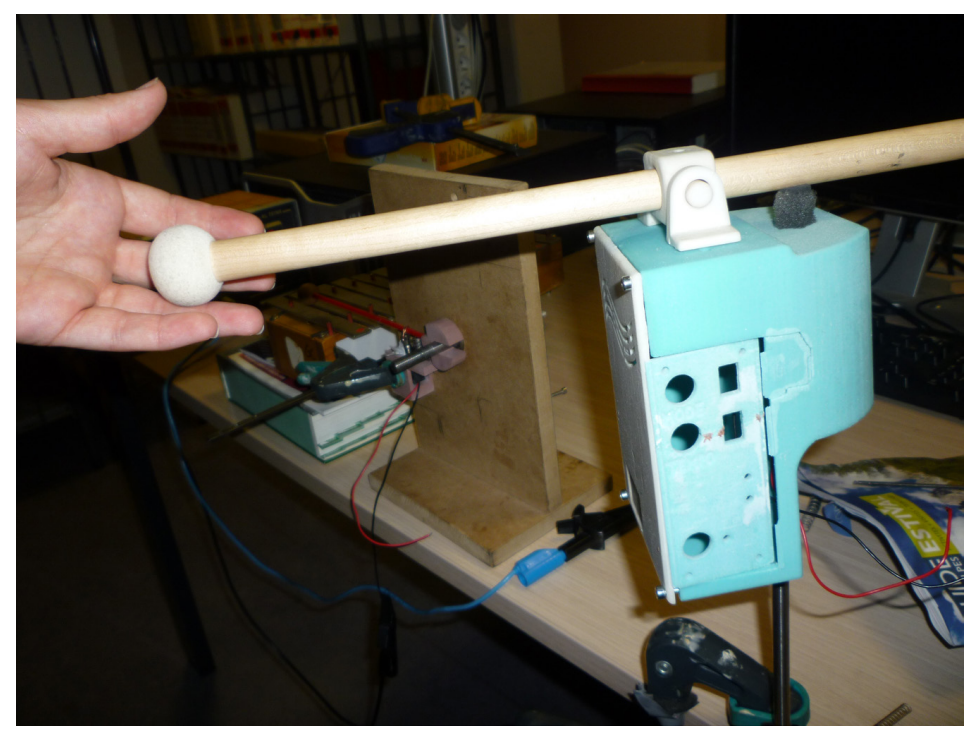

Figure 12. Version of the MEM produced using the Zprinter ${ }^{\circledR}$ manufacturing process (year 2012).

contributes to the low cost price of the product. Moreover, each child or specialized school could have their own personalized MEM: colour, logo, name, etc. This product is dedicated to anybody wishing to play music. The final version allows the direct connection of all DC personal interfaces (universal 3.5mm mini-jack connector). It is easy to assemble for everyone. The power supply and user interface are connected directly inside the main housing. This makes it easy for anybody to set up the system before a concert. The requirement of the music teacher is met too: the DC can choose a variety of musical options thanks to the electronic control card. Moreover, these chosen options help to adapt the product to the user capabilities and motivations. The electronic card is located in the housing and controls the electromagnet. A standard PC power supply powers the electronic card and the electromagnet (Figure 13). 


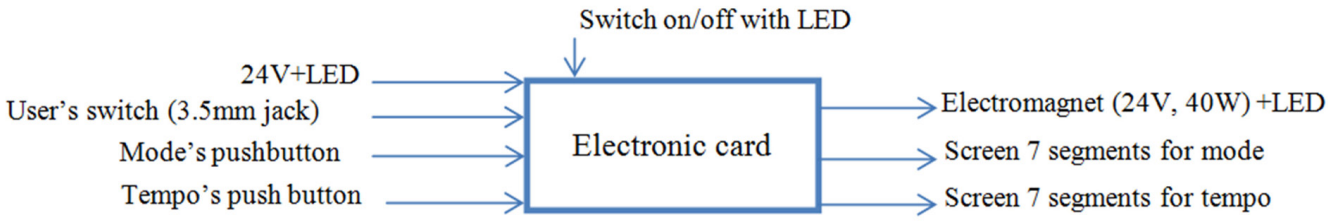

Figure 13. Electronic card functions.

This card is programmed to activate the electromagnet in ten different modes. These modes were defined together with the medical staff and the music teachers. They make it possible for the drum to be played by people with different kinds of disabilities and in different musical conditions.

- Mode 0 or "Normal mode": the user presses the switch to activate the electromagnet. This is then deactivated only when the user releases the contactor. Holding the switch for more than $6 \mathrm{~s}$ can damage the electromagnet, which is why the card has a protection: the electromagnet is automatically deactivated after $5 \mathrm{~s}$.

- Mode 1 or "Rebound mode": even if the switch is pressed for a long time, the electromagnet is deactivated almost instantly after the drum has been hit.

- Mode 2 or "Reversed Mode": the electromagnet is activated when the user releases the switch.

- Mode 3 or "Burst Mode": a long press on the switch activates a burst of sound at a frequency defined by a tempo.

- Modes 4 to 9: when the user presses the switch this activates the electromagnet causing it to play the associated sequence once.

Modes 3 to 9 can be played at a specific tempo. The electronic card enables 10 tempos: $\boldsymbol{e}=60$ then 75 , 90, 105, 120, 135, 150, 165, 180 and 200 (defined by the music teacher).

To select the desired mode and tempo, the card is equipped with 2 push-buttons and associated screens (each press on the switch increments the screen). One tempo can be applied to one mode. Finally, the card has three LEDs confirming proper functioning of the electromagnet, user switch and power supply respectively (Figure 14). The system is held in position on a cymbal stand with a pressure screw. The cymbal stand can thus be placed in the desired position.

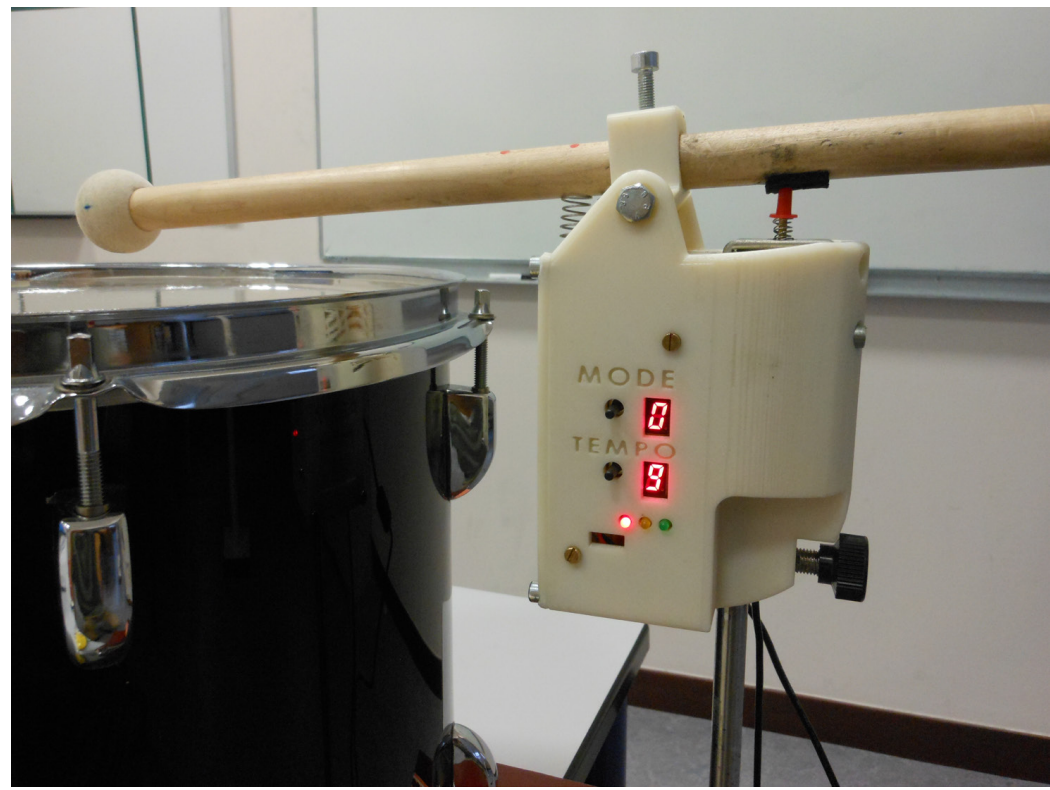

Figure 14. Final version of the MEM produced using professional FDM technology (year 2015). 
The technical choices made for this product have allowed it to be adapted to the many forms of disability encountered over the course of this eight-year experience. The first four modes described above make such adaptation possible. The others modes (four to nine) make it possible to adapt the system to the type of music proposed by the music teacher.

\section{Results}

From September 2015 to January 2016, four concerts have been organized with disabled children. Each time a different child has manipulated alone the proposed MEM. In each case, the three button placed in different locations have been manipulated autonomously and efficiency by the disabled musician. It was possible for him to choose the right tempo and the right mode for each song.

This design methodology included therapists, musical teachers, engineers and engineering students using $\mathrm{RP}$ has been tested. This experiment allows to observe common steps from UCD and ABAB methodologies. Effectively, these two approaches are based on iterations. In the case study proposed, each new iteration uses a new RP technology. It facilitates on the same time the progressive validations of different technical functions of the product, and the knowledge about RP technology possibly usable to manufacture the final product. The Table 1 presents the use of these technologies during the case study proposed.

Table 1. The use of RP Technologies in the design process.

\begin{tabular}{|c|c|c|c|c|}
\hline Iteration & RP Technologies & Type of validations & Advantages & Disadvantages \\
\hline 1 & Zprinter & Design, size, the assembly, & Printing velocity, low cost & $\begin{array}{l}\text { Low rigidness, non-functional } \\
\text { pieces }\end{array}$ \\
\hline 2 & Z-builder & $\begin{array}{l}\text { Little parts, the assembly and } \\
\text { functionality }\end{array}$ & $\begin{array}{l}\text { Complexity of shapes, little } \\
\text { pieces }\end{array}$ & Expensive, low resilience \\
\hline 3 & Low-cost FDM Rep/Rap & $\begin{array}{l}\text { Colours, type of material, complete } \\
\text { functionability, product behaviour }\end{array}$ & Cheap, resilience & Slow, precision \\
\hline 4 & Professional FDM & Final product proposition & Cheap, precision, resilience & \\
\hline In the future & CNC machining & & $\begin{array}{l}\text { Industrialisation, important } \\
\text { number of products. }\end{array}$ & $\begin{array}{l}\text { Expensive, long manufacturing } \\
\text { time }\end{array}$ \\
\hline
\end{tabular}

The first column shows the iteration number in the design process. In the third column, the type of validations concerning the current case study have been noticed. It is important to notice that different RP technologies were used to validate progressively different aspects of the product: aesthetics, functionality, assembly, rigidness, etc. Finally, the two last columns resume advantages and disadvantages of these RP technologies used.

\section{Discussion}

Between 2006 and the creation of the first version of the electromechanical drumstick system, five DC actively participated in the development and evolution of the product. During the successive development periods, the perception of the researchers evolved and the organization of meetings and experiments changed. In the last years, the decision was taken to perform all the evaluation activities with at least one representative from each specialized area. If anybody was missing, the meeting or the activity was cancelled. In the case study presented, the authors observed the behaviour of the multidisciplinary team made up of healthcare staff, music teachers and designers. They selected an appropriate UCD methodology with geared towards ability-based design. This consists in focusing on ability and hence leverages the full range of human potential. They decided to apply a personalized product strategy, mainly to prevent device abandonment (Cruz et al., 2016) and implement a product configurability strategy (Salvador \& Forza, 2004).

In this case study, participants manufactured personalized product in the disabled domain taking into account all of these factors, as well as some available RP technologies. This experiment could be achieved in the university context where RP technologies are available for students and engineers. Some others products for DC to play the music have been validated with the same approach. It helps not only the design team to find the best design solution for the user but also the students to learn a lot about RP technologies.

The final product is currently used by five DC who actively participated in its development. The majority of DC have "similar" disabilities. Effectively, the great number of options available through the participation of musicians and occupational therapists provide a variety of interactions with the product: 
- The "human interface" part is personalized based on user ability and constitutes a separate part of the system;

- The "control" part can transform the standard signal coming from the human interface. It makes it possible to control the operational part;

- The "operational" part is the electromechanical drumstick system. It can be used to play most percussion instruments and comes with options, as described in the previous section;

- The design of the product (aesthetics), especially the housing, can be personalised to the specialized educational school or to the DC.

The MEM and others products designed and manufactured by the AE2M association include the control system and the operational parts. The design choices allow for product variety (benefiting the DC and the music teacher) together with stability. The approach is the same for each product, and it is possible to strategically choose some specific parts or functions that can allow an effective and low-cost personalisation of the product.

\section{Conclusion}

AE2M developed many MEM prototypes during this project, which began many years ago. The final product will be handled by the DC, the customers, the family, the educational professionals in the specialized schools and the music teachers. The context of study imposed a multidisciplinary team bringing together engineers, medical staff, music professionals and the DC. Different prototypes were tested by many different DC and in many different musical contexts. Thanks to the iterative phases of the methodology and the RP technologies used, the final product met the requirements of the multiple users identified. The study showed that each interaction and experimentation can influence and modify technical choices.

Over the years, the prototype evolved, encouraging the designers to try different RP technologies. Based on the requirements of all the users and the musical, technical and medical collaboration, the choice was finally narrowed down to the professional FDM manufacturing process.

The claims of this paper can be summarized as follow:

- Throughout the design process, the type of prototype and associated building scenario must be linked to the evolution of the product idea;

- RP technologies have to be adapted to the kind of functions to be validated (with or without the final users). Different technologies have been employed at different stages of the process because of the necessity to prove the advantage, to demonstrate or to validate any modification or idea;

- To identify the different iteration of the design process, it can be very useful to select one RP technologies by iteration;

- For engineering students, this kind of case study method helps a lot to learn about RP technologies and design methods;

- The choice of RP technology is not only influenced by the users, customers and others professional actors but by the selected management and economic strategy too.

The complex housing manufactured using RP technology was one of the key components of the MEM. To lower the cost of this complex system, the most adapted RP technology had to be found. In 2006, only one simple housing was integrated into one MEM without option, without aesthetical reflexing and personalization (see Figure 8). Independently of the cost of RP technology which has quickly came down over that almost a decade, today the cost of producing the complete MEM fell by 70\%, using the FDM manufacturing process. Moreover, this last version integrates many musical and interaction personalized options.

\section{Perspectives}

In the future, the main idea will be to design a commercialised product personalized to each user specificities. The most effective way to solve these problems is to focus on the design phase. Approaches based on UCD, product customization or personalization, project platforms, product configuration, modularization and mass customization all reflect this idea. Although highly varied, these approaches and strategies complement each other and may offer the key to finding the right balance between product variety, which may go so far as to 
include product personalization, and production volume, with its requirement for product design stability. Even if the volume will not necessary be important, some tools may be adaptable in the current context.

Not only did the authors and other actors really contribute to the wellbeing and social integration of DC by manufacturing the product, they also furthered ideas about better product design process, product accessibility and market adaptability.

\section{Acknowledgements}

The researchers wish to thank all off the students and teachers who actively participated in the development of the different versions of the products. They thank the healthcare staff (especially Emilie Cornu), the music teachers (especially Jacques Cordier) and the engineers (especially Alain Di Donato). Special thanks to Alexia who left us three years ago.

\section{References}

Boer, H., Holweg, M., Kilduff, M., Pagell, M., Schmenner, R., \& Voss, C. (2015). Making a meaningful contribution to theory. International Journal of Operations \& Production Management, 35(9), 1231-1252. http://dx.doi.org/10.1108/1JOPM-03-2015-0119.

Brangier, E., \& Barcenilla, J. (2003). Concevoir un produit facile à utilizer. Paris: Editions d’Organisation.

Chavarriaga, R., Hurtado, M. N., Bolanos, M., Loaiza, J. A., Mayor, J. M., Valencia, M., \& Aguilar-Zambrano, J. (2014, October 10-13). Multidisciplinary design of suitable assistive technologies for motor disabilities in Colombia In: Global Humanitarian Technology Conference (GHTC) (pp. 1-6). San José, USA.

Cruz, D. M. C., Emmel, M. L. G., Manzini, M. G., \& Braga Mendes P. V. (2016). Assistive technology accessibility and abandonment: challenges for occupational therapists. The Open Journal of Occupational Therapy, 4(1)Art. 10.

Elprama, S. A., Duysburgh, P., Bleumers, L., \& Jacobs, A. (2013). Developing assistive technology with multidisciplinary teams: a frontend procedure to stimulate collaboration and manage expectations. Assistive Technology Research Series, 33, 959-965.

International Organization for Standardization. (2010). ISO 9241-210: ergonomics of human-system interaction - part 210 - humancentred design for interactive systems. Geneva: ISO.

Lancioni, G. E., Tota, A., Smaldone, A., Singh, N. N., O’Reilly, M. F., Sigafoos, J., Oliva, D., \& Montironi, G. (2007). Extending the evaluation of novel microswitch technology for small responses in children with profound multiple disabilities. Assistive Technology, 19(1), 11-16. PMid:17461286. http://dx.doi.org/10.1080/10400435.2007.10131861.

Magnier, C., Thomann, G., \& Villeneuve, F. (2012). Seventeen projects carried out by students designing for and with disabled children: identifying designers' difficulties during the whole design process. Assistive Technology, 24(4), 273-285. http://dx.doi.org/10.108 $0 / 10400435.2012 .669808$.

Pruski, A. (2010). A unified approach to accessibility for a person in a wheelchair. Robotics and Autonomous Systems, 58(11), 1177-1184. http://dx.doi.org/10.1016/j.robot.2010.07.001.

Pullin, G. (2011). Design meets disability. Cambridge: M.1.T. Press.

Salvador, F., \& Forza, C. (2004). Configuring products to address the customization responsiveness squeeze: A survey of management issues and opportunities. International Journal of Production Economics, 91(3), 273-291. http://dx.doi.org/10.1016/j.jpe.2003.09.003.

Sperandio J.-C. (2007). Designing technological devices for a normal population, namely also including disabled people and the elderly. Pistes, 9(2). Retrieved in 2017, June 19, from https://pistes.revues.org/2975\#quotation

Story, M. F. (1998). Maximizing usability: the principles of universal design. Assistive Technology, 10(1), 4-12. PMid:10181150. http:// dx.doi.org/10.1080/10400435.1998.10131955.

Thomann, G., Di Donato, A., Cordier, J., \& Thony, J. (2008, September 4-5). Ergonomic adaptation of musical materials project: first experience feedbacks of a two-year multidisciplinary human experience of mechanical engineering students. In: 10th International Conference on Engineering and Product Design Education (pp. 196-203). Barcelone, Spain: Publishing Institution.

Veytizou, J., Xuereb, H., \& Thomann, G. (2013, March 11-13). Design of a clip product based on customer needs for playing acoustic music. In: 23th CIRP Design Conference (pp. 367-376). Bochum, Germany: Publishing Institution. 